\title{
Fernández Ruiz, Jorge, Tratado de derecho elec- toral, México, Porrúa, UNAM, 2010, XXXI-547 pp. [Prólogo de Raúl Padilla López]
}

Jorge Fernández Ruiz es una de las figuras más destacadas del derecho mexicano. Ninguna duda cabe después de ver la abundancia de proyectos y publicaciones en los cuales se ha embarcado en los últimos diez años, especialmente vinculados al derecho administrativo: justicia, contencioso, contratos, radio, televisión y telecomunicaciones, servicios públicos municipales, derechos de los usuarios de seguros privados, control de la administración pública, Estado empresario, fuerzas armadas, agua, turismo, salud pública, urbanismo, etcétera. También se ha ocupado de revisar figuras señeras de nuestra historia, y lo ha hecho con maestría, como se constata en su Juárez y sus contemporáneos. Sus colecciones de derecho administrativo, tanto en el plano nacional como internacional, no tienen parangón. Una visita a la Biblioteca Jurídica Virtual del Instituto de Investigaciones Jurídicas nos da cuenta de ello (http://biblio.juridicas.unam.mx). Ahora, nos entrega su obra más reciente: un tratado de derecho electoral.

Aunque el título nos anuncia que estamos en presencia de un libro de derecho electoral; el análisis del mismo nos permite advertir que debe calificarse como una obra integral, pues como lo señala el prologuista, los dieciséis capítulos de que consta la obra, conjuntan elementos tanto de la teoría del Estado como de la ciencia política, la filosofía, la historia y, por supuesto, el derecho. En tal sentido, el lector 
encontrará algo más que derecho electoral, aunque entenderá que eso forma parte del cimiento conceptual del mismo.

Para comenzar la incursión en esta materia, el autor inicia con la democracia, pero no se agota en lo absoluto ahí. A partir de tal noción el autor después nos aproximará al poder, al Estado, al gobierno, al concepto del derecho electoral, a la representación, a los partidos políticos e incluso, a las "patologías electorales". Esto nos permite advertir de entrada la riqueza de la obra, cuya vastedad se advierte desde el título que utiliza el autor: Tratado de derecho electoral. Por supuesto, habrá que reconocer que esta vastedad rebasa la acepción que nos proporciona la Real Academia Española al referir en su diccionario que tratado significa "escrito o discurso de una materia determinada". La obra de nuestro distinguido autor va más allá del escrito o del discurso, es una enciclopedia del derecho electoral y de algunos temas que le son afines.

Para quienes la revisión de los temas mencionados puede parecer excesiva, conviene señalar que nuestro autor explica que tiene una razón de ser: para la cabal comprensión del derecho electoral, conviene tener un conocimiento, aunque sea somero, de la democracia, del poder, del Estado y del gobierno, de ahí el énfasis que se advierte en los primeros cuatro capítulos de la obra (pp. 1-121). Semejante a la máxima de Terencio, en derecho electoral todo lo que tenga que ver con estas materias no resulta ajeno.

El capítulo primero (pp. 1-9), dedicado al estudio de la democracia abre con la definición de este concepto universal. Nuestro autor cita aquel ya clásico discurso de Lincoln, para honrar a los caídos en Gettysburg, donde señala "que la democracia es el gobierno del pueblo, por el pueblo, para el pueblo”. A continuación se ocupa de ir revisando algunas de las connotaciones que ha adquirido la democracia, especialmente en el plano constitucional: como forma de Estado, como forma de gobierno y como forma de vida. Al final, nuestro autor hace algunas críticas relevantes sobre el carácter que tiene la democracia en el mundo contemporáneo: "la falacia de la democracia... se pone de manifiesto aun en el más somero de los análisis, pues la democracia no puede existir auténticamente donde unos cuantos, con la fuerza de sus aportaciones económicas, decide quiénes serán contendientes a ocupar ciertos cargos públicos, incluido el más importante del país", en clara alusión al modelo estadounidense. Por supuesto, la visión crí- 
tica permea el presente libro y nos parece claro que puede extenderse a otras latitudes, mucho más cercanas.

Al ocuparse del análisis del poder, el autor señala que es "una de las más grandes ambiciones del ser humano: por ello, desde hace milenios es un tema que atrae la atención de filósofos, teólogos, políticos, sociólogos, juristas, psicólogos y estudiosos de otras disciplinas". Sin duda este tema que ha merecido numerosos libros es uno de los elementos más sobresalientes en el conjunto de factores que explican las transformaciones de los sistemas políticos y electorales.

Los cuatro capítulos iniciales proporcionan un marco explicativo de las transformaciones que han marcado el diseño de los sistemas electorales en cualquier Estado contemporáneo. Con tal bagaje, el lector encontrará en el quinto capítulo (pp. 123-180), los elementos que le permitirán observar las transformaciones que en el ámbito electoral federal se han dado en México. El análisis no se concreta al siglo pasado, sino que remontándose al siglo XIX avanza más allá y llega hasta la época precortesiana, con el ánimo de no dejar cabo suelto en la revisión histórico-cultural de la forma en que se han elegido, nombrado y designado gobernantes en esta geografía que hoy habitamos. Sorprende la afirmación del autor al señalar de inicio que "el empleo del voto electoral como medio de designación de los depositarios de las funciones del poder público se remonta en México a la época precortesiana, por lo menos, a la época en que los aztecas dominaban Tenochtitlan, Texcoco y Tacuba" (p. 123).

No para ahí, en cada reforma, hasta llegar a la de 2008, Fernández Ruiz va señalando inconsistencias y faltantes en el diseño electoral, todo para resaltar la necesidad de una reforma en la cual se beneficie, sobre todo, ese etéreo y endeble ideal que es la democracia. No debe olvidarse que los grandes faltantes en el diseño electoral, no son en ocasiones sino descubrimientos que se hacen con la puesta a prueba del sistema. En no pocas ocasiones son los tribunales los que descubren tales faltantes, impuestos como están a desentrañar el sentido de las normas y hacer una interpretación sistemática, funcional o de otro tipo.

El sexto capítulo (pp. 181-217) lo dedica nuestro autor a explicar el rol de lo electoral para la configuración de una disciplina jurídica autónoma. La definición que nos proporciona es la siguiente: "conjunto sistematizado de conocimientos y principios relativos al estudio de la regulación jurídica positiva de las instituciones y procesos electorales, 
y de los mecanismos para la adopción de resoluciones concernientes a temas públicos trascendentales, mediante el voto popular".

Esta definición resulta lo suficientemente amplia para dar cabida a las preocupaciones que los jueces constitucionales y los académicos tienen respecto de la inclusión de otras figuras, relativas a la participación ciudadana, en el ámbito de lo electoral. Aquí habrá que recordar que tanto la Suprema Corte de Justicia de la Nación, como el Tribunal Electoral, han emitido diversos criterios que intentan configurar la esfera de lo electoral. Llamaríamos la atención a la tesis X/2009 de la Sala Superior, cuyo rubro da cuenta de tal preocupación: "REFERÉNDUM O PLEBISCITO COMO INSTRUMENTO DE DEMOCRACIA DIRECTA. LOS ACTOS RELACIONADOS CON ÉSTOS SON IMPUGNABLES A TRAVÉS DEL JUICIO PARA LA PROTECCIÓN DE LOS DERECHOS POLÍTICO-ELECTORALES DEL CIUDADANO".

Pero el autor no se detiene sólo en la aproximación epistémica. A continuación, en el capítulo séptimo esboza ya los perfiles de la teoría de la representación política. Su aproximación la inicia con la representación jurídica, para llevarnos a las diversas teorías que sostienen la idea de representación en el plano político, explicitando además las diversas formas de representación política que han existido y existen.

A continuación, en el capítulo octavo, se ocupa de los partidos políticos (pp. 241-287). Se cuestiona sobre qué es un partido político y nos propone una definición: un partido político "es la agrupación permanente de una porción de la población, vinculada por ciertos principios y programas, derivados de sus intereses o de su interpretación del papel que corresponde a los depositarios del poder público y a los diversos segmentos sociales en el desarrollo socioeconómico del Estado, con miras a hacerse de dicho poder para, en ejercicio del mismo, poner en práctica los principios y programas que postula” (p. 244).

A continuación revisa los antecedentes históricos de los partidos. Tal ejercicio lo relaciona con los temas de mayor interés al analizar los partidos políticos: las causas, los elementos, las funciones, las diversas clasificaciones que admiten, el financiamiento y por supuesto, la crisis que experimentan. Someramente nos presenta al final del capítulo octavo el régimen de los partidos políticos en México.

El capítulo noveno lo dedica al tema del sistema electoral. Y cabe decirlo, lo hace con verdadera maestría, al detenerse en cada uno de los elementos que lo conforman y que permiten al lector entender la complejidad de estos diseños institucionales en las sociedades contempo- 
ráneas. Bastaría revisar este capítulo para darse cuenta de los alcances que tiene la organización de las elecciones en un país de las proporciones del nuestro, sin contar los que corresponden a India o Rusia.

Sin embargo nuestro autor, incansable, continúa y nos ofrece una revisión del sistema que hemos adoptado en nuestro país para la elección de los ejecutivos, tanto federal, como locales, así como de los miembros del Poder Legislativo, también federal y locales. En este rubro se detiene en el tema de la representación proporcional y de manera sencilla nos permite una aproximación a las diversas fórmulas electorales, que con su sencillez permiten una comprensión que a veces creemos negada para los abogados, algunas veces fugitivos de los cálculos matemáticos.

El capítulo duodécimo es el que más debe llamar la atención, pues nos permite, como lo dije, advertir que estamos ante un trabajo enciclopédico que busca ofrecernos el compendio de todas las facetas que tocan lo electoral. Este capítulo se dedica a lo que el autor denomina la "patología electoral". Ahí están esas prácticas que forman parte del imaginario social: la mapachería electoral y los ilícitos electorales. Así, el autor nos lleva por senderos que incluyen el acarreo, las actas ilegibles, la alquimia electoral, la anulación del voto, la caída del sistema, el carrusel, las casillas itinerantes, las casillas madrugadoras, la casilla zapato, el fraude cibernético, la operación tamal, el ratón local, el robo hormiga, los tacos de votos, el tianguis de credenciales, el terrorismo electoral y las urnas embarazadas, por citar algunos de esos fenómenos que han sido atestiguados en la historia electoral de este y otros países. En los ilícitos electorales, don Jorge Fernández Ruiz nos permite el repaso tanto de los delitos como de las infracciones administrativas electorales. El capítulo decimotercero lo dedica a la administración pública electoral, es decir a la organización del Instituto Federal Electoral (pp. 435-482), ese sui generis órgano autónomo del Estado, mismo que ha venido a vivificar la interpretación del derecho a través de los cuestionamientos que ha merecido su configuración y sus atribuciones, últimamente en el ámbito de la justicia constitucional.

El capítulo decimocuarto se dedica a la justicia electoral federal, esta última tanto en sede administrativa (ante el IFE) como en sede jurisdiccional (ante el Tribunal Electoral y la propia Suprema Corte de Justicia de la Nación) (pp. 483-508). Evidentemente, son pocos los trabajos que se han escrito sobre tales temáticas, pero el autor nos ofrece ya una visión panorámica que enriquece la obra. 
El capítulo final está dedicado a la teoría del acto electoral (pp. 50936), cuya aproximación resulta indispensable para el operador del derecho electoral, pues permite advertir, como se hace en el derecho civil o en el derecho penal, los componentes que dan valor a las actuaciones de los actores en el derecho electoral, y que constituyen un parámetro de referencia para los órganos encargados de las diversas facetas de la función electoral.

Habría mucho más que hablar del libro, que como ha quedado de manifiesto es una obra que viene a llenar un vacío en nuestra bibliografía. Sin embargo, es labor titánica tratar de compendiar todo lo que aquí se nos ofrece y en el colmo, ello podría impedirnos manifestar algunas opiniones sobre la persona del autor.

En lo personal, don Jorge Fernández Ruiz es poseedor de una gran calidad humana; cuando hablamos de él pensamos en la sencillez, amabilidad y cordialidad; afirmamos que ha sabido cultivar y transmitir y que se ha distinguido en diversas facetas: ciudadano, profesor, jurista y amigo.

Hemos afirmado que la labor académica, especialmente en el ámbito de las ciencias sociales, es ante todo un compromiso con la sociedad, y que en el ámbito del derecho, el académico consagra sus desvelos, preocupaciones y afanes al mejoramiento del sistema jurídico que regula la convivencia social, a la vez que pretende encontrar los fundamentos de tal orden para entender sus transformaciones y necesidades. Esas frases dibujan a nuestro autor: una vida entera dedicada a la investigación, difusión y docencia jurídicas; una vida plena de pasión por el derecho. Como muchos otros amigos, conocimos a don Jorge en el Instituto de Investigaciones Jurídicas de la UNAM, lugar común de trabajo. Su vocación e interés por el derecho público resulta contagioso. Y sus múltiples invitaciones a participar en los eventos y proyectos que cotidianamente organiza son el mejor aliciente para muchos de los beneficiarios. Por ello, el ver esta nueva obra nos sirve de ejemplo e inspiración.

Referida nuestra opinión sobre el autor y su obra, y dado que el maestro Fernández Ruiz no deja de sorprendernos, no nos queda sino esperar el siguiente libro, ya anunciado en la introducción, sobre el derecho procesal electoral ( $\mathrm{p}$. XXX). Estamos seguros que habrá de ser, como éste, una obra de indispensable consulta por los estudiosos del derecho electoral mexicano. Máxime cuando se advierte que será posiblemente esta nueva obra la que enfatice los alcances que tendrá 
la nueva reforma constitucional de junio de 2011, en el ámbito de los derechos de naturaleza político-electoral.

Debo decir, por último, que aún quedan temas por definir, ya no en el ámbito doctrinal, pues en la obra lo hace nuestro autor, sino en la creación normativa que compete al órgano revisor de la Constitución y al legislador ordinario. Algunos están plasmados en la iniciativa presentada por el Ejecutivo Federal el 15 de diciembre de 2009:

- Reelección inmediata de legisladores federales, munícipes y jefes delegacionales en el Distrito Federal.

- Reducción del número de integrantes de las cámaras del Congreso de la Unión.

- Candidaturas independientes.

- Segunda vuelta en la elección presidencial.

- Revocación de mandato.

- Ratificación del gabinete por el Senado.

Estamos convencido que la discusión que se genere para construir el andamiaje normativo que requieren estas figuras, tendrá en esta obra un referente obligado. Por ello, la felicitación al autor, maestro y amigo, por proporcionar una herramienta sumamente útil para el estudio previo que habrá de culminar con la transformación de nuestro sistema político-electoral.

David Cienfuegos Salgado

Secretario de Estudio y Cuenta de la Sala Superior del Tribunal Electoral del Poder Judicial de la Federación 